\title{
ARTICLE
}

\section{Effectiveness of self-shielding type cyclotrons}

\author{
Kazuyoshi Masumoto $^{\mathrm{a}^{*}}$, Hirohisa Iiduka ${ }^{\mathrm{b}}$, Shingo Sato ${ }^{\mathrm{b}}$, Kazufumi Kuga $^{\mathrm{b}}$, Toshioh Fujibuchi ${ }^{\mathrm{c}}$, Masahiro Sasaki ${ }^{\mathrm{d}}$, \\ Toshimitsu Fukumura ${ }^{\mathrm{e}}$, Hajime Nakamura ${ }^{\mathrm{a}}$ and Akihiro Toyoda ${ }^{\mathrm{a}}$ \\ ${ }^{a}$ High Energy Accelerator Research Organization, Oho 1-1, Tukuba, Ibaraki 305-0801, Japan, ${ }^{b}$ Nuclear Safety Technology \\ Center,Hakusan 5-1-3-101, Bunnkyo-ku, Tokyo 112-8604, Japan, 'Ibaraki Prefectural University of Health Sciences,Ami 4669-2, \\ Inashiki-gun, Ibaraki 300-0394, Japan, ${ }^{d}$ Foundation for Biomedical Research and Innovation, Minatojima Minamimachi 2-2, \\ Chuo-ku, Kobe, Hyogo 650,0047, Japan, ${ }^{e}$ National Institute of Radiological Sciences, Anagawa 4-9-1, Inage-ku, \\ Chiba 253-8555, Japan
}

\begin{abstract}
Cyclotrons of the self-shielding type have recently been employed for use in medical applications. Herein, we investigated the shielding power of five types of self-shields by measuring neutron flux from inside to outside the self-shield. Measurements were performed for five types of self-shields through the activation of Au foils, TLD, and the dosimeter with CR-39 as track detector. During the production of ${ }^{18} \mathrm{~F}$, the thermal neutron flux near the target box was found to be $10^{7} \mathrm{~cm}^{-2} \cdot \mathrm{s}^{-1}$. The neutron flux in the cyclotron vault was $10^{1-2} \mathrm{~cm}^{-2} \cdot \mathrm{s}^{-1}$. The use of self-shielding type cyclotrons reduced neutron flux, which became five orders of magnitude lower than the initial flux. Samples collected from the cyclotron vault material showed no residual activity. We concluded that the induced radioactivity of the material surrounding the self-shield, as a result of activation by neutrons from the cyclotron, is negligible. These results are important to implement proper radiation control of materials surrounding the cyclotron and for the decommissioning of the facility.
\end{abstract}

Keywords: cyclotron;PET; self-shield; neutron fluence;TLD ;CR-39;activation detector

\section{Introduction}

Positron emission tomography (PET) has been widely used for the inspection of diseases such as cancer. In Japan, about 150 cyclotrons have been used for radioisotope production in hospitals. The main radioisotope used for PET is ${ }^{18} \mathrm{~F}\left(\mathrm{~T}_{1 / 2}=110 \mathrm{~min}\right)$. The neutrons are produced by the $(\mathrm{p}, \mathrm{n})$ reaction and cause activation of materials surrounding the cyclotron. Recently, cyclotrons with various types of self-shields have been installed to allow for a reduction in the required wall thickness of a cyclotron vault. The neutron spectrum and dose in the vicinity of self-shields have been measured $[1,2]$. In the design of cyclotron facility, it is important to maintain the dose of radiation outside the cyclotron vault below the regulation level. The reduction of neutron activation is also important for the radiation control of materials surrounding the cyclotron and decommissioning of facility. Several authors used activation detectors to measure the neutron flux [3-5]. In this work, we used the activation detectors Au foil, TLD, and CR-39 to monitor neutron fluence inside the cyclotron vault in five types of cyclotrons covered with self-shields. For systematic investigation of the neutron shielding effect, we also measured the activity of various materials collected from the cyclotron room.

*Corresponding author. Email: kazuyoshi.masumoto@kek.jp

\section{Experimental}

\subsection{Facilities and operational conditions}

Five facilities, namely, IBA cyclone 10/5, CTI RDS-111, Sumitomo Heavy Industry CYPRIS-HM-7, MINItrace, and HM-20, were selected for this study. The operational conditions used are listed in Table $\mathbf{1 .}$ Proton energies ranged from 7 to $20 \mathrm{MeV}$. The main isotope produced in all facilities was ${ }^{18} \mathrm{~F}$; in addition, several facilities produced ${ }^{11} \mathrm{C}$. As shown by the data given in Table 1 , cyclotron shielding was either of a monolayer (concrete doped with B and polyethylene) or a multilayer type (heavy concrete coupled with the use of polyethylene and $\mathrm{Pb}$ ).

\subsection{Neutron monitoring during operation}

To monitor the thermal and epithermal neutron fluence during ${ }^{18} \mathrm{~F}$ production, a pair of $\mathrm{Au}$ foils (thickness $20 \mu \mathrm{m}$ ) with and without a $\mathrm{Cd}$ cover (thickness $1 \mathrm{~mm}$ ) was set near the target folder inside the self-shield, in the shield, and outside the shield. Irradiation conditions (acceleration energy, beam current, and irradiation time) are listed in Table 1. A Ge detector was used to measure the activity of one Au-foil. Relative activities of other foils were measured by positioning all foils on an imaging plate and obtaining the photo-stimulated luminescence (PSL) simultaneously. 
Table 1. Operational conditions of five cyclotron facilities that were used in the survey.

\begin{tabular}{|c|c|c|c|c|c|}
\hline & 1 & 2 & 3 & 4 & 5 \\
\hline Cyclotron & IBA cyclone 10/5 & CTI RDS-111 & Cypris HM-20 & Cypris MINItrace & Cypris HM-7 \\
\hline $\begin{array}{c}\text { Self-shield } \\
\text { materials }\end{array}$ & $\begin{array}{c}\text { Concrete doped with } \\
\text { B and Polyethylene }\end{array}$ & Concrete & $\begin{array}{c}\text { Polyethylene+Pb+ } \\
\text { Concrete }\end{array}$ & $\begin{array}{c}\text { Polyethylene+Pb+ } \\
\text { Concrete }\end{array}$ & $\begin{array}{c}\text { Polyethylene+ } \\
\text { Concrete }\end{array}$ \\
\hline Shield thickness & $80 \mathrm{~cm}$ & $65 \mathrm{~cm}$ & $5+5+90 \mathrm{~cm}$ & $30+15+26 \mathrm{~cm}$ & $20+50 \mathrm{~cm}$ \\
\hline Production & & & & & $\mathrm{F}-18$ \\
\hline Energy & $10 \mathrm{MeV}$ & $11 \mathrm{MeV}$ & $20 \mathrm{MeV}$ & $9.6 \mathrm{MeV}$ & $7 \mathrm{MeV}$ \\
\hline One day irradiation & & & & & $60 \mu \mathrm{A}$ \\
\hline Beam current & $30 \mu \mathrm{A}$ & $36 \mu \mathrm{A}$ & $50 \mu \mathrm{A}$ & $34 \mu \mathrm{A}$ & $0.6 \mathrm{~h}$ \\
\hline Irradiation time & $1 \mathrm{~h}$ & $1.1 \mathrm{~h}$ & $0.25 \mathrm{~h}$ & $1.5 \mathrm{~h}$ & \\
\hline 1 month operation & & & & & $34 \mu \mathrm{A}$ \\
\hline Average current & $17 \mu \mathrm{A}$ & $36 \mu \mathrm{A}$ & $50 \mu \mathrm{A}$ & $36 \mathrm{~h}$ & $12.55 \mathrm{~h}$ \\
\hline Irradiation time & $25.9 \mathrm{~h}$ & $27 \mathrm{~h}$ & $5.8 \mathrm{~h}$ & & \\
\hline
\end{tabular}

A detailed description of this procedure can be found in reference [6]. Neutron fluence was divided by operation time to obtain neutron flux.

\subsection{Dose monitoring in the cyclotron vault}

In the cyclotron vault, TLD UD-813 PQ4 (Panasonic) and the dosimeter QuIxel Badge with CR-39 (Nagase Landauer) were placed on the wall, floor, and outside the self-shield to monitor the $\gamma$ and neutron dose. The monitoring was performed for one month. Average current and operation times are listed in Table 1. Thermal neutron flux $\left(\mathrm{cm}^{-2} \cdot \mathrm{s}^{-1}\right)$ was obtained after multiplying the TLD data (Sv) by the conversion factor that was obtained for the graphite pile standard neutron field at KEK.

\section{Results and discussion}

\subsection{Neutron flux from the inside to the outside of the self-shield}

\subsubsection{Neutron emission}

In all the cyclotron facilities studied in this work, the negative ion $\left(\mathrm{H}^{-}\right)$is accelerated and converted to a proton beam by bombarding a carbon stripper foil. The target material is ${ }^{18} \mathrm{O}$-enriched water and neutrons are produced via the ${ }^{18} \mathrm{O}(\mathrm{p}, \mathrm{n}){ }^{18} \mathrm{~F}$ reaction. Therefore, neutron fluence during irradiation is largely dependent on the yield of ${ }^{18} \mathrm{~F}$. When ${ }^{11} \mathrm{C}$ is produced via the ${ }^{14} \mathrm{~N}(\mathrm{p}, \alpha){ }^{11} \mathrm{C}$ reaction, neutrons are not typically emitted by this reaction. Instead, neutrons were likely emitted by the other reactions of materials surrounding the target holder. In this work, the $\left({ }^{11} \mathrm{C} /{ }^{18} \mathrm{~F}\right)$ ratio of neutron yields for $20 \mathrm{MeV}$ irradiation was 0.089 . Using this factor, irradiation time was normalized to the condition of ${ }^{18} \mathrm{~F}$ production.

\subsubsection{Neutron attenuation by self-shield}

Thermal and epithermal neutron fluxes were calculated from the ${ }^{198} \mathrm{Au}$ activity of $\mathrm{Au}$ foils in the cases with and without the Cd cover. In this work, the detected amount of the fast neutron reaction product,
${ }^{196} \mathrm{Au}$, was negligible. Therefore, we concluded that the PSL signal was caused by $\beta$-ray emitted from ${ }^{198} \mathrm{Au}$.

Figure 1 shows neutron flux for IBA cyclone 10/5 under the conditions of $10 \mathrm{MeV}$ and $30 \mu \mathrm{A}$, for ${ }^{18} \mathrm{~F}$ production. The self-shield was composed of concrete doped with $\mathrm{B}$ and polyethylene, and the thickness of the shield was $80 \mathrm{~cm}$. Thermal neutron flux on the surface of the cyclotron was $6.6 \times 10^{5} \mathrm{~cm}^{-2} \cdot \mathrm{s}^{-1}$. The epithermal neutron flux was $28 \%$ of the thermal neutron flux. At the thicknesses of 14 and $22 \mathrm{~cm}$ (measured relative to the inner surface of the self-shield), the neutron flux decreased by one and two orders of magnitude, respectively. At the thicknesses of 60 and $79 \mathrm{~cm}$, no ${ }^{198} \mathrm{Au}$ activity was detected.

Figure 2 shows the results obtained for CTI RDS-111 under the conditions of $11 \mathrm{MeV}$ and $36 \mu \mathrm{A}$. The thermal neutron flux from the target to the outer surface of the shield attenuated from $1.4 \times 10^{7}$ to $5.3 \times 10^{3} \mathrm{~cm}^{-2} \cdot \mathrm{s}^{-1}$. Inside the self-shield, $\mathrm{Cd}$ ratios were close to 1 ; thus, thermal neutron flux could not be measured. Thermal neutron flux in the upper part of the shield was $2.2 \times 10^{4}$ $\mathrm{cm}^{-2} \cdot \mathrm{s}^{-1}$; this value was higher than the one measured in the lateral part.

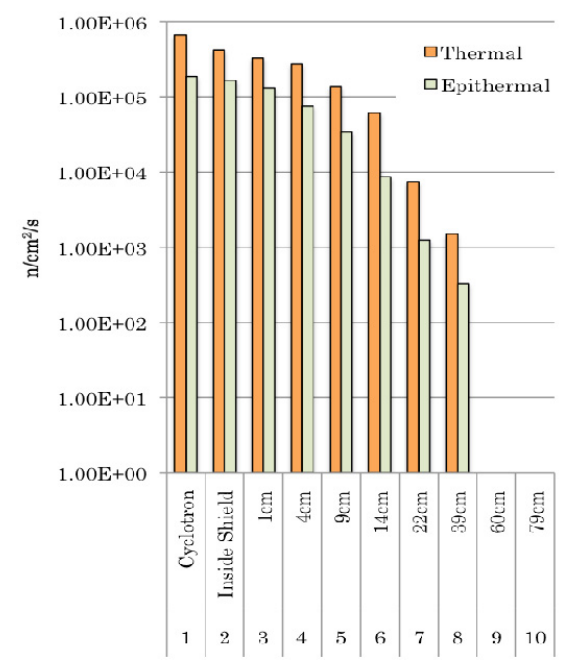

Figure 1. Attenuation of thermal and epithermal neutron radiation, from inside to outside of the self-shield of IBA. cyclone. 10/5. 


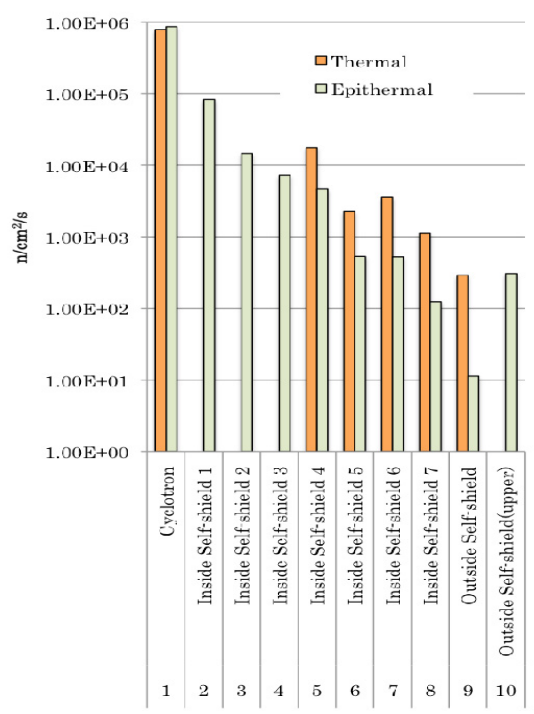

Figure 2. Attenuation of thermal and epithermal neutron radiation, from the inside to the outside of the self-shield of CTI RDS- 111.

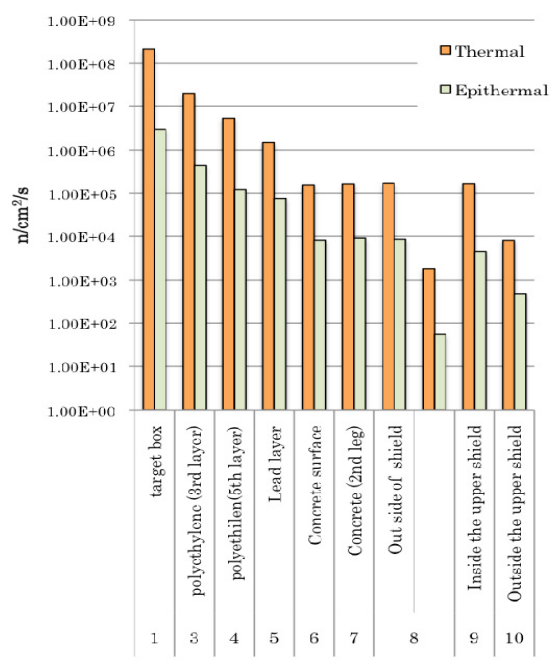

Figure 4. Attenuation of thermal and epithermal neutron radiation, from the inside to the outside of the self-shield of Cypris MINItrace.

Figure 3 shows the results obtained for Cypris HM-20 under irradiation conditions of $20 \mathrm{MeV}$ and $50 \mu \mathrm{A}$. Thermal neutron flux values inside and outside the target box were $6.8 \times 10^{7}$ and $3.3 \times 10^{6} \mathrm{~cm}^{-2} \cdot \mathrm{s}^{-1}$, respectively. At the $55 \mathrm{~cm}$ thickness of the shield, the flux was 4 orders of magnitude smaller than the value measured inside target box. The activity of ${ }^{198} \mathrm{Au}$ could not be detected at the thickness of $98 \mathrm{~cm}$.

Figure 4 shows the results obtained for Cypris MINItrace under the conditions of $9.6 \mathrm{MeV}$ and $34 \mu \mathrm{A}$. Thermal and epithermal neutron fluxes inside the target box were $2.1 \times 10^{8}$ and $3.0 \times 10^{6} \mathrm{~cm}^{-2} \cdot \mathrm{s}^{-1}$, respectively. As the shield thickness of the upper part is thinner than the horizontal thickness, neutron leakage from the thinner part was four times higher.

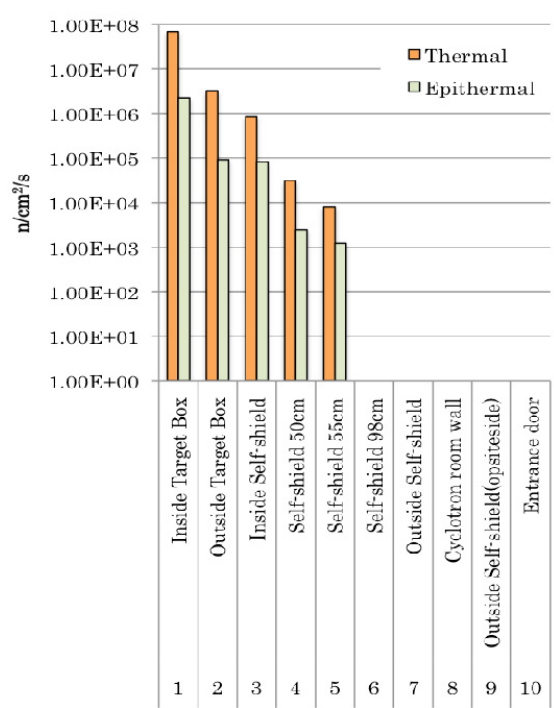

Figure 3. Attenuation of thermal and epithermal neutron radiation, from the inside to the outside of the self-shield of Cypris HM-20.

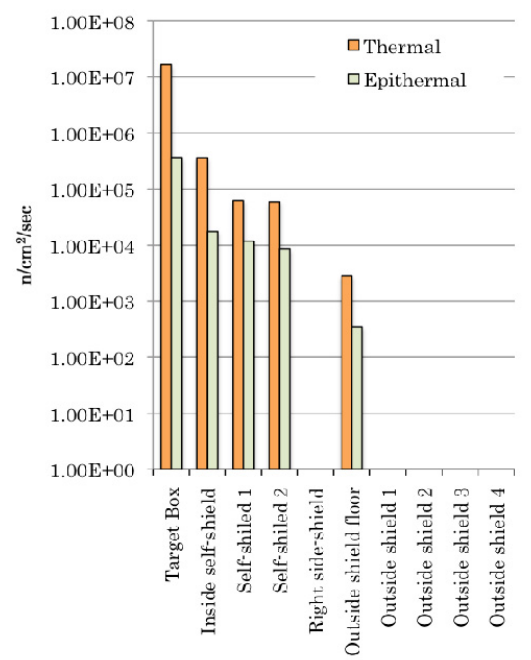

Figure 5. Attenuation of thermal and epithermal neutron radiation from the inside to the outside of the self-shield of Cypris .HM-7.

Figure 5 shows the results obtained for Cypris HM-7 under the conditions of $7 \mathrm{MeV}$ and $60 \mu \mathrm{A}$. Among all five facilities that were surveyed, this one had lowest proton energy but highest beam current. Thermal neutron flux outside the target box was $1.7 \times 10^{7} \mathrm{~cm}^{-2} \cdot \mathrm{s}^{-1}$. It was found that neutrons leaked throughout a gap between the shield and the floor.

During ${ }^{18} \mathrm{~F}$ production, the thermal neutron flux near the target box was about $10^{7} \mathrm{~cm}^{-2} \cdot \mathrm{s}^{-1}$ and did not depend on the irradiation energy. The thermal neutron flux may depend on the structure near the target assembly. We found that the thermal neutron flux was generally larger than the epithermal neutron flux, but the Cd-ratios were from 1 to 3 .

Because the upper part of the shield was thinner than 
Table 2. Neutron and $\gamma$-ray dose rates and thermal neutron fluxes during irradiation in the cyclotron vault.

\begin{tabular}{|ccccccc|}
\hline Facility & & 1 & 2 & 3 & 4 & 5 \\
\hline $\begin{array}{c}\gamma \text {-ray } \\
(\mathrm{mSv} / \mathrm{h})\end{array}$ & av. & $1.2 \mathrm{E}-01$ & $1.0 \mathrm{E}-02$ & $7.5 \mathrm{E}-02$ & $8.8 \mathrm{E}-03$ & $3.1 \mathrm{E}-01$ \\
& max. & $2.6 \mathrm{E}-01$ & $4.8 \mathrm{E}-02$ & $1.7 \mathrm{E}-01$ & $1.6 \mathrm{E}-02$ & $8.8 \mathrm{E}-01$ \\
& min. & $2.2 \mathrm{E}-02$ & $3.7 \mathrm{E}-04$ & ND & $5.4 \mathrm{E}-04$ & $1.2 \mathrm{E}-02$ \\
\hline fast neutron & av. & $4.7 \mathrm{E}-04$ & $1.7 \mathrm{E}-02$ & $3.9 \mathrm{E}-02$ & $2.0 \mathrm{E}-03$ & $2.9 \mathrm{E}-01$ \\
$(\mathrm{mSv} / \mathrm{h})$ & max. & $1.3 \mathrm{E}-03$ & $1.4 \mathrm{E}-01$ & $1.7 \mathrm{E}-01$ & $4.8 \mathrm{E}-03$ & $1.3 \mathrm{E}+00$ \\
& min. & ND & $8.2 \mathrm{E}-04$ & ND & $0.0 \mathrm{E}+00$ & $1.2 \mathrm{E}-02$ \\
\hline Thermal & av. & $1.9 \mathrm{E}-04$ & $2.1 \mathrm{E}-03$ & $5.4 \mathrm{E}-03$ & $3.7 \mathrm{E}-04$ & $2.9 \mathrm{E}-02$ \\
neutron & max. & $7.4 \mathrm{E}-04$ & $1.4 \mathrm{E}-02$ & $2.6 \mathrm{E}-02$ & $1.1 \mathrm{E}-03$ & $9.3 \mathrm{E}-02$ \\
$(\mathrm{mSv} / \mathrm{h})$ & min. & ND & $1.0 \mathrm{E}-04$ & $7.9 \mathrm{E}-04$ & $4.7 \mathrm{E}-05$ & $3.5 \mathrm{E}-03$ \\
\hline $\begin{array}{c}\text { Thermal } \\
\text { neutron flux }\end{array}$ & av. & $1.5 \mathrm{E}+00$ & $1.3 \mathrm{E}+01$ & $4.5 \mathrm{E}+01$ & $2.4 \mathrm{E}+01$ & $4.4 \mathrm{E}+02$ \\
$\left(\mathrm{n} / \mathrm{cm}^{2} / \mathrm{s}\right)$ & min. & $3.9 \mathrm{E}+00$ & $2.0 \mathrm{E}+01$ & $7.0 \mathrm{E}+01$ & $9.1 \mathrm{E}+01$ & $7.0 \mathrm{E}+02$ \\
& & ND & $5.6 \mathrm{E}+00$ & $9.1 \mathrm{E}+00$ & $5.1 \mathrm{E}+00$ & $1.5 \mathrm{E}+02$ \\
\hline
\end{tabular}

the horizontal part, neutron penetration through the upper part was higher, as is shown in Figure 2. The presence of a gap between the shield and the floor was also important because, as shown in Figure 5, it admitted neutron leakage.

\subsubsection{Neutrons in the cyclotron vault}

The neutron dose was very low in the cyclotron vault owing to the self-shield, and its level could not be precisely detected by $\mathrm{Au}$ activation. Thus, to improve the detection sensitivity, the dosimeters were placed in the vault for one month. Neutron flux was calculated by dividing the neutron fluence by the total operation time during measurement.

Table 2 lists the average, the maximal and the minimal values of different doses obtained by the dosimeter. The doses of $\gamma$-ray, thermal neutron, and fast neutron radiation were measured in addition to the thermal neutron flux, which was calculated using the TLD. Measurements are reported for all five facilities that were studied. Average dose rates of $\gamma$-rays and fast neutron radiation ranged from several tens to several hundreds $\mu \mathrm{Sv} \cdot h^{-1}$. On the other hand, a typical dose rate of thermal neutrons during the operation was found to be several $\mu \mathrm{Sv} \cdot \mathrm{h}^{-1}$.

Thermal neutron flux during operation was almost always lower than $10^{2} \mathrm{~cm}^{-2} \cdot \mathrm{s}^{-1}$. However, when any narrow gap between the shield and the floor existed, neutrons passed through the gap, as in the case of Cypris HM-7.

\subsection{Activation of materials in the cyclotron vault}

A proper handling of activated substances is important for radiation safety in the accelerator facility. Recently, the clearance system of activated materials has been started in Japan. In order to release activated accelerator components to the environment, a careful procedure should be performed. It is important to confirm that the activation is negligible outside the self-shield. Thus, we collected pipes bolts and plates, which were made of iron, steel, brass, and aluminium.
These samples were kept in the same position for more than five years. No radioactivity could be detected after a 1-day long measurement of $\gamma$-ray activity using a Ge detector. The lower detection limit of our system was below the clearance levels for ${ }^{60} \mathrm{Co},{ }^{65} \mathrm{Zn},{ }^{54} \mathrm{Mn}$, and other radioactive substances.

\section{Conclusion}

The results of our study are summarized as follows:

(1) Neutron production during RI production.

Neutrons were mostly produced from the target by ${ }^{18} \mathrm{~F}$ production. Near the target, the neutron flux was of the order of $10^{7} \mathrm{~cm}^{-2} \cdot \mathrm{s}^{-1}$. Flux of thermal neutrons was one order of magnitude higher than that of epithermal neutrons. As a result of shielding, the neutron flux was reduced by five orders of magnitude. Neutron fluence was found to be dependent on the production yield of ${ }^{18} \mathrm{~F}$.

(2) Dose rate in the cyclotron vault during operation.

Dose rate of thermal neutrons during operation was several $\mu \mathrm{Sv} \mathrm{h}^{-1}$, and except for the case of HM-7, the neutron flux was under $10^{2} \mathrm{~cm}^{-2} \cdot \mathrm{s}^{-1}$.

(3) Metal samples collected from the cyclotron vault. No residual activity was detected in metal samples collected from the cyclotron vault.

Typical cyclotron operation time is about a few hours per day. We conclude that the activation of materials surrounding the self-shield is negligible.

\section{Acknowledgements}

The authors thank the staff of the National Cancer Center Research Center for Cancer Prevention and Screening Japan (Tokyo), Uozumi Clinic (Kumamoto), the Oita University Advanced Molecular Imaging Center (Oita), Aizawa Hospital (Matsumoto), and Fukuoka Central Health Evaluation and Promotion Center (Fukuoka) for their help in this work. 


\section{References}

[1] N. E. Hertel, M. P. Shannon, Z.-L. Wang, M. P. Valenzano, W. Mengesha and R. J. Crowe, Neutron measurements in the vicinity of a self-shielded PET cyclotron, Radiat. Prot. Dosim. 108(2004), pp. 255-261.

[2] G. S. Pant and S. Senthamizhchelvan, Initial experience with an $11 \mathrm{MeV}$ self-shielded medical cyclotron on operation and radiation safety, J. Med. Phys. 32(2007), pp. 118-123.

[3] M. Sakama, T. Saze, T. Tanii, H. Maezawa, K. Maeda, K. Sato K, E. Honda and H. Nishitani, Determination of neutron fluxes at the self-shielded PET cyclotron and electron linac apparatus of Tokushima University hospital using activation foil method. Jpn J. Rad. Safety Manage.7(2008), pp.138-147. (in Japanese).

[4] G.Horitsugi, T. Fujibuchi, I. Yamaguchi, A. Eto, Y.
Iwamoto, H. Hashimoto, S. Hamada, S. Obara, H. Watanabe and J. Hatazawa, Radiologic assessment of a self-shield with boron-containing water for a compact medical cyclotron, Radiol. Phys. Technol., 5(2012), pp.129-137.

[5] T. Fujibuchi, G. Horitsugi, I. Yamaguchi, A. Eto, Y. Iwamoto, S. Obara, T. Iimori, Y. Masuda, H. Watanabe and J. Hatazawa, Comparison of neutron fluxes in an 18-MeV unshielded cyclotron room and a $16.5-\mathrm{MeV}$ self-shielded cyclotron room, Radiol. Phys. Technol., 5(2012), pp.156-165.

[6] K. Masumoto, A. Toyoda, K. Eda and T. Ishihara, Measurement of the spatial distribution of neutrons in an accelerator room by the combination of activation detectors and an imaging plate, Rad. Safety Manage. 1(2002), pp.12-16. 